\title{
Efficacy of Tranexamic Acid in Decreasing Blood Loss during and after Cesarean Section: A Randomized Case Controlled Prospective Study
}

\author{
A. V. Chandak, Immi Gupta, Sreemayi C
}

\begin{abstract}
Postpartum hemorrhage is among the leading causes of maternal mortality throughout the world. Severe blood loss contributes to the increased blood transfusion risk with its concerned inherent adverse events and therefore increased rate of emergency re-operative interventions such as arterial ligation or hysterectomy. It also can lead to protracted anemia, particularly in low or median income countries. Objective: To study the efficacy and safety of tranexamic acid in reducing blood loss during and after the lower segment cesarean section. Method: A randomized, case controlled, prospective study was conducted on 100 women undergoing lower segment cesarean section (LSCS) Fifty of them were given tranexamic acid Igm IV 20 mins before skin incision and were compared with fifty others to whom tranexamic acid was not given. Blood loss was collected and measured during two periods. The first period was from placental delivery to end of LSCS and second from the end of LSCS to 2 hours postpartum. RESULTS: Tranexamic acid significantly reduced the quantity of blood loss from the end of LSCS to 2 hours postpartum: $79.0 \pm 14.18 \mathrm{ml}$ in the study group versus $128.57 \pm 23.72 \mathrm{ml}$ in the control group $(p=0.0001)$. It also significantly reduced the quantity of blood loss from placental delivery to 2 hours post-partum: $308.80 \pm 43.60 \mathrm{ml}$ in the study group, versus $349.18 \pm 42.17 \mathrm{ml}$ in the control group. $(P=0.0001)$. No complications or side effects were reported in either group. CONCLUSION: Tranexamic acid significantly reduced the amount of blood loss during and after the lower segment cesarean section and its use was not associated with any side effects or complication like thrombosis. Tranexamic acid can be used safely and effectively in women undergoing LSCS.
\end{abstract}

Keywords: Tranexamic acid, Cesarean section

\section{Introduction}

Caesarean section rates have increased as high as 25 to $30 \%$ in many areas of the world(1) and so have the complications associated with it, one of the major being post-partum haemorrhage leading to increase in the maternal mortality rates. Postpartum hemorrhage (PPH) is the leading or at least among the five top causes of death(2). 14 million women suffer from PPH each year, of whom 1-2\% die within 2-4 hours after the onset of bleeding 2 to $11 \%$ of them show anemia lat $\neg$ er in their life (3). According to World Health Organization (WHO) definition, PPH occurs when the clinical amount of blood loss is about $500 \mathrm{ml}$ after vaginal deliv $\neg$ ery or $1000 \mathrm{ml}$ after CS. Even lesser volume (un $\neg$ der $200 \mathrm{ml}$ ) of blood loss is considered as health threatening factor for parturient specially in low and median income countries with high preva $\neg$ lence of anemia (4). Therefore, it is important to control the bleeding during and after LSCS.

Tranexamic acid is a synthetic derivative of the amino acid lysine that exerts its antifibrinolytic effect through the reversible blockade of the lysine binding sites on plasminogen molecules. Intravenous administration of tranexamic acid has been shown to be very useful in reducing blood loss and incidence of blood transfusion in number of surgeries like coronary artery bypass, oral surgery, liver transplantation, total hip or knee arthroplasty, and urinary tract surgery.

In this study, the efficacy and safety of tranexamic acid in the reducing the blood loss during and after LSCS was investigated.

\section{Methods}

This is a prospective randomized case controlled study. Randomization was done by the rule of odds and even into two groups, $\mathrm{T} \& \mathrm{C}$, of 50 patients each. In group $\mathrm{T}, 20$ minutes before taking the skin incision $1 \mathrm{gm}$ tranexamic acid was given slowly intravenously over 5 minutes and the blood loss was compared with that in 50 others to whom tranexamic acid was not given. Full term primiparas / multiparas with singleton pregnancy being delivered by LSCS were included in the study while subjects having medical and problems involving the heart, liver, kidney and brain and having blood disorders were excluded from the study. Subjects having allergy to tranexamic acid, history of thromboembolic disorders, abnormal placentation, severe pre-eclampsia, multiple pregnancy, macrosomia polyhydromnios and those requiring blood transfusion due to anemia were also excluded from the study.

After a detailed pre- anesthetic evaluation of selected patients, laboratory tests including hemoglobin level, hematocrit, blood sugar (fasting), electrocardiogram, blood urea, serum creatinine, prothrombin time, and International Normalised Ratio (INR) were carried out. Hemoglobin and hematocrit levels were ascertained for every patient on the day before surgery in the hospital laboratory. LSCS was carried out under subarachnoid block using 2- $2.5 \mathrm{ml}$ of $0.5 \%$ hyperbaric bupivacaine after an informed written consent. Blockade up to T4- T6 level was considered adequate level of anesthesia. After delivery of the neonate, 20 unit of oxytocin in $500 \mathrm{ml}$ normal saline were given at the rate of $8 \mathrm{mU} / \mathrm{min}$ intravenously.

Monitoring of the pulse rate, blood pressure, Pulse Oximetry $(\mathrm{SpO} 2)$ and Electrocardiograph (ECG) was carried out every $2 \mathrm{~min}$ up to $10 \mathrm{~min}$ of starting the study drug; then every 5 min until the delivery of baby and thereafter every $15 \mathrm{~min}$ 


\section{International Journal of Science and Research (IJSR) \\ ISSN (Online): 2319-7064}

Index Copernicus Value (2015): 78.96 | Impact Factor (2015): 6.391

until the end of the surgery The blood loss was measured following placental delivery to the end of the surgery, and from the end of the operation to 2 hours after birth. Uterine contractility, placental separation, neonatal manifestations, and side effects caused by tranexamic acid were noted.

\section{Measuring blood loss}

The quantity of blood loss $(\mathrm{mL})=$ (weight of the used materials in both the periods - weight of the materials prior to the surgery) + the volume sucked in the suction bottle after placental delivery in $\mathrm{mL}$. In addition, the pads used after completion of LSCS to 2 hours postpartum were separately weighed. Amniotic fluid and the amount of blood lost before placental delivery was thus not included in measuring blood loss in the study.

\section{Result}

There was no statistically significant difference among the two groups in terms of the demographic profile (Table 1). Hemodynamic parameters such as pulse rate, blood pressure, respiratory rate and $\mathrm{SpO} 2$ were seen to be comparable after statistical analysis using the student $t$ - test $(\mathrm{P}>0.05)$. Indications of surgery were comparable in both the groups (Table 2). All LSCS were done under spinal anesthesia, the duration of surgery being 57.25 minutes in the study group and 56.57 minutes in the controlled group, the difference being no significant statistically.

Table 1

\begin{tabular}{|c|c|c|c|}
\hline Parameters & Group T & Group C & P value \\
\hline Age (in years ) & $24.3 \pm 2.6$ & $23.6 \pm 2.5$ & 0.99 \\
\hline Height (in cms) & $158.9 \pm 3.4$ & $159.2 \pm 3.3$ & 0.99 \\
\hline Weight (in kgs) & $57.7 \pm 4.7$ & $58.0 \pm 5.5$ & 0.798 \\
\hline Gravidity & $1.3 \pm 0.4$ & $1.2 \pm 0.4$ & 0.212 \\
\hline
\end{tabular}

Table 2

\begin{tabular}{|c|c|c|}
\hline Indication & Group T & Group C \\
\hline Cord around neck & 8 & 6 \\
\hline MSL & 12 & 15 \\
\hline Breech & 42 & 48 \\
\hline CPD & 18 & 22 \\
\hline NPOL & 20 & 9 \\
\hline
\end{tabular}

There was statistically significant difference in the quantity of the blood loss from the time of placental delivery till the end of LSCS. $(\mathrm{P}=0.0001)$. There was also statistically significant difference in the quantity of the blood loss from end of LSCS to 2 hours postpartum $(\mathrm{P}=0.0001)$. (Table 3 )

Also the incidence of postpartum hemorrhage (PPH) i.e. $>$ $500 \mathrm{~mL}$ blood loss was lower in the study group than in the control group. $(\mathrm{P}=0.049)$ (Table 4$)$

Table 3

\begin{tabular}{|c|c|c|}
\hline Group & $\begin{array}{c}\text { Placental delivery to } \\
\text { the end of LSCS }(\mathrm{ml})\end{array}$ & $\begin{array}{c}\text { End of LSCS to } 2 \mathrm{hrs} \\
\text { postpartum }(\mathrm{ml})\end{array}$ \\
\hline Study & $308.80 \pm 43.60$ & $79.0 \pm 14.18$ \\
\hline Control & $349.18 \pm 42.17$ & $128.57 \pm 23.72$ \\
\hline P- Value & 0.0001 & 0.0001 \\
\hline
\end{tabular}

Table 4

\begin{tabular}{|c|c|c|}
\hline $\begin{array}{c}\text { Blood loss from placental delivery } \\
\text { to 2 hrs postpartum }(\mathrm{ml})\end{array}$ & Study & Control \\
\hline$<500 \mathrm{~mL}$ & 42 & 32 \\
\hline$>500 \mathrm{~mL}$ & 8 & 18 \\
\hline
\end{tabular}

\section{Discussion}

Tranexamic acid exerts its antifibrinolytic effect by blocking the lysine-binding locus of the plasminogen and plasmin molecules, thereby preventing the binding of plasminogen and plasmin to the fibrin substrate. TXA also inhibits the conversion of plasminogen to plasmin by the plasminogen activators. TXA is a potent inhibitor of fibrinolysis was first reported by Okamoto in 1962.(5) Since then, TXA has been widely used to treat heavy menstrual bleeding(6) and to reduce blood loss in elective surgery where it reduces blood transfusion by about one-third 7,8.

During placental delivery, fibrinogen and fibrin are rapidly degraded, whereas plasminogen activators and fibrin degradation products (FDP) increase due to activation of the fibrinolytic system. This activation can last upto $6-10$ hours postpartum, causing more bleeding, which can be taken care of by anti-fibrinolytic agents. Therefore, the use of TXA appears to reduce the blood loss.

This study showed that tranexamic acid significantly redues bleeding from time of placental delivery to 2 hours postpartum in $\operatorname{LSCS}(\mathrm{P}=0.001)$. This study shows significant decrease in the incidene of $>500 \mathrm{~mL}$ blood loss in the study group as compare to control group. Similar study carried out by Ming-ying Gai et al (9) in China showed that tranexamic acid significantly reduces bleeding from the time of placental delivery to 2 hours post partum. The study showed significant decrease in the incidence of $>500 \mathrm{ml}$ blood loss in the study group as compared to control group (P-0.029). Zheng et al (10), showed similar results after vaginal delivery. Similar study carried out in India by Mayur et al.(8) showed comparable results reducing the blood loss in the study group. On searching for similar literature, we found a few studies where TXA has been used in LSCS patients. It has been found to be useful in $\mathrm{PPH}$ also, a Cochrane review (2011) regarding this being ample evidence.[11]. A double- blind randomized clinical trial by Karski et al. used TXA pre- operatively for prevention of bleeding after cardiopulmonary bypass in a very high dose of $10 \mathrm{~g}$ intravenously over $20 \mathrm{~min}$ before sternotomy followed by another $10 \mathrm{~g}$ infused intravenously over 5 h.[12]]. Horrow et al. used prophylactic TXA in the dose range of $2.5-40 \mathrm{mg} / \mathrm{kg}$ in patients undergoing cardiac surgeries and concluded that the dose of $10 \mathrm{mg} / \mathrm{kg}$ followed by $1 \mathrm{mg} / \mathrm{kg} / \mathrm{h}$ decreased bleeding after extracorporeal circulation. Larger doses did not provide additional hemostatic benefit in the study.[13] the study by Karski et al. too, a high dose of infusion at the rate of $10 \mathrm{~g}$ intravenously over $5 \mathrm{~h}$ after a bolus of $10 \mathrm{~g}$ showed no additional benefit over placebo infusion.[12]

There was no significant alteration in the vital signs of subjects following tranexamic acid administration. There were no abnormalities in hemoglobin, liver and renal function, and urine analysis. The incidence of thrombosis 


\section{International Journal of Science and Research (IJSR) \\ ISSN (Online): 2319-7064 \\ Index Copernicus Value (2015): 78.96 | Impact Factor (2015): 6.391}

during pregnancy and puerperium is 5-6 times higher then that in the general population (14). When the antifibrinolytic drug tranexamic acid is administered, the increased risk of post partum thrombosis after LSCS should be considered. In the present study, not a single patient developed thrombosis and incidences of side effects like nausea, vomiting and diarrhea were not statistically significant by difference in the two groups. These been corraborated by other studies $(9,14)$.

\section{Conclusion}

Tranexamic acid significantly reduced the amount of blood loss during and after the lower segment cesarean section and its use was not associated with any side effects and.or complication like thrombosis. Thus, tranexamic acid can be used safely and effectively in subjects undergoing LSCS.

\section{References}

[1] Kambo I , Bedi N, Dhillon BS, Saxena NC. A critical appraisal of cesarean section rates at teaching hospitals in India. Int J Gynaecol Obstet 2002;79:151- 8.

[2] AbouZahr C. Antepartum and postpartum haemorrhage. In: Murray CJL, Lopez AD, eds. Health dimensions of sex and reproduction: the global burden of sexually transmit $\neg$ ted diseases, HIV, maternal conditions, perinatal disor $\neg$ ders, and congenital anomalies. Cambridge, MA, Harvard School of Public Health on behalf of the World Health Or $\neg$ ganization and the World Bank, 1998 (Global Burden of Disease and Injury Series, No. III):165-189.

[3] AbouZahr C. Global burden of maternal death and dis $\neg$ ability. Br Med Bull. 2003;67:1-11.

[4] Lalonde A, Daviss B-A, Acosta A, et al. Postpartum hemor $\neg$ rhage today: ICM/FIGO initiative 2004-2006. Int J Gynaecol Obstet.2006;94:243-253.

[5] Roberts I. Tranexamic acid: a recipe for saving lives in traumatic bleeding. J Tehran Heart Cent 2011; 6:178.

[6] Lukes AS, Kouides PA, Moore KA. Tranexamic acid: a novel oral formulation for the treatment of heavy menstrual bleeding. Womens Health 2011; 7:151-8.

[7] Caglar GS, Tasci Y, Kayikcioglu F, Haberal A. Intravenous tranexamic acid use in myomectomy: a prospective randomized double-blind placebo controlled study. Eur J Obstet Gynecol Reprod Biol 2008; 137:227-31. Epub 2007 May 11.

[8] Mayur G, Purvi P, Ashoo G, Pankaj D. Efficacy of tranexamic acid in decreasing blood loss during and after caesarean section: a randomized case controlled prospective study. J Obstet Gynecol India 2007; 57:22730.

[9] Gai MY, Wu LF, Su QF et al. A clinical observation of blood loss reduced by tranexamic acid during and after caesarian section: a multi-central trial, randomized trial science direct Eur J Obstet Gynecol Reprod Biol. 2004;112:154-7.

[10] Yang H, Zheng S, Shi C et al. Clinical study on the efficacy of tranexamic acid in reducing postpartum blood lose: a randomized, comparative, multicenter trial Chin J Obstet gynecol 2001;6:590-2.

[11] Novikova N, Hofmeyr GJ. Tranexamic acid for preventing postpartum haemorrhage. Cochrane Database Syst Rev 2010;7:CD007872.
[12] Karski JM, Teasdale SJ, Norman P, Carroll J, VanKessel K, Wong P, et al. Prevention of bleeding after cardiopulmonary bypass with high- dose tranexamic acid. Double- blind, randomized clinical trial. J Thorac Cardiovasc Surg 1995;110:835- 42.

[13] Horrow JC, Van Riper D F, Strong MD, Grunewald KE, Parmet JL. The dose- response relationship of tranexamic acid. Anesthesiology 1995; 82:383- 92.

[14]Lindoff C, Rybo G, Astedt B. Treatment with tranexamic acid during pregnancy, and the risk of thrombo-embolic complications. Throm Haemost.1993;70:238-40 